\title{
The Extended Theory of Planned Behavior in Context of Risky Driving - Speeding
}

\author{
Eva Rošková ${ }^{1}$ Eva Stopjaková ${ }^{1}$ \\ ${ }^{1}$ Comenius University in Bratislava, Faculty of Arts, Department of Psychology, Bratislava, Slovakia
}

\begin{abstract}
Based on the extended version of the Theory of Planned Behavior (TPD) the purpose of this study was to estimate the influence of factors that determine dangerous driving - speeding. Additionally, the role of subjective, and descriptive norms with respect to self-reported and actual speeding behavior was also investigated. A questionnaire survey was conducted on 101 drivers ages 18-57, distinguished according to the gender. Results showed significant relationship between main constructs of TPB and speeding behavior. The strongest relation has been shown between habit and self-reported and actual speeding of drivers. According to the results of regression analyses, determinants of speeding behavior were sex, subjective norms, perceived behavioral control, habit and intention to speed. The regression model accounted for 69, 5\% of variance. Males compared to women reported speeding more often.
\end{abstract}

Keywords: Theory of Planned Behavior, attitudes, norms, intention, habit, speeding

\section{Introduction}

Speeding behavior on the roads is globally considered as the most important factor causing death and injuries in traffic accidents (European Commission, 2003). High speed reduces the control of the vehicle, increases the fatality risk in traffic and the negative impact of high speed on road safety has been confirmed by many researches (e.g. Dinh, Kubota, 2013). What motivates drivers to exceed the allowed speed, despite being aware of the risk of accidents with increasing vehicle speed? Current studies (e.g. Warner, Wallen, 2006; SARTRE 3, 2004) demonstrate that drivers perceive the relationship between speeding and accident risk, the problem is that they do not believe that the risk applies also to themselves. Speeding is among drivers often associated with the belief that their ability to drive fast is better than the capabilities of the other drivers, that despite the high speeds they drive securely, they reach the destination faster and that the increased speed delivers them driving thrills and drivers more enjoy it.

\section{Theory of Planned Behavior and speeding}

One of the most influential model which helps to understand decision making and motivation in relation to speeding behavior is the Theory of Planned Behavior (TPB) (Ajzen, 1991) supporting the socio-psychological frame of behavior. In traffic psychology, TPD was used in several context, e.g. to explain the violation of traffic rules by pedestrians and drivers, driving under influence of alcohol, use/not use of safety belts, speeding behavior (Paris, Broucke, 2008).

According to the TPD model (Ajzen, 1991) volitional behavior (speeding included) is to a large extent determined by the intention to perform that behavior. Intention represents a motivating factor, which indicates how much effort people are willing to spend to behave in a planned manner. Generally, the stronger is the intention to behavior, the more likely action will be performed. Intention is a function of three social cognitive variables: attitudes towards the behavior, social norms with regard to the behavior, and perceived behavioral control (Fig.1).

An attitude can be defined as the positive or negative evaluation of the expected outcomes of the behavior, both in terms of instrumental (e.g., needing less time to get to the destination) and affective outcomes (e.g., pleasure or fear of driving fast). The affective components of attitudes are not explicitly taken into account in the model. The 'attitude' factor in this model is determined by cognitive beliefs (action is reasoned and planned). On the cognitive level people can be aware of that certain behavior (exceeding speed limit) is dangerous and not permitted, but they like such a behavior, because it gives them a good feeling, makes them happy. The NHTSA 
(2002) survey shows that $36 \%$ of participants have positive attitude to fast driving. Speeding prefer more men than women, younger drivers, people with higher financial income, people living in cities and those who drive frequently. Parker et al. (1992) found that cognitive as well as affective component of attitude has a significant effect on the intention to speed.

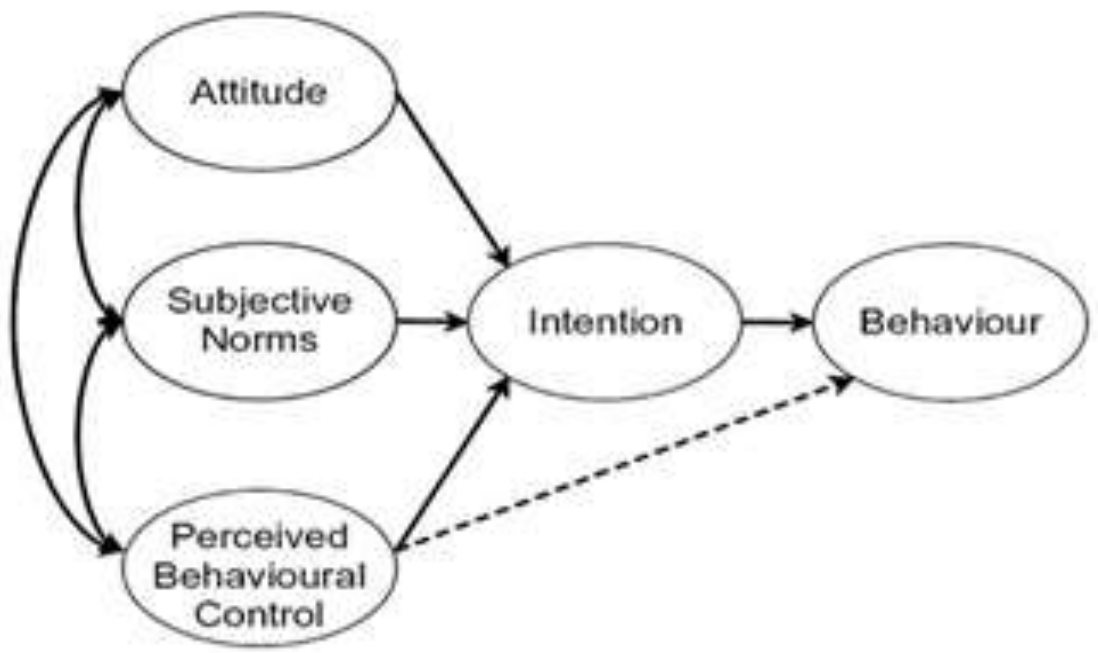

Fig. 1: Theory of Planned Behavior

Subjective norms refer to the perceived social influence to engage in the behavior of interest, and are derived from the behavior and/or direct feedback of significant others or people we trust. The extent to which these norms influence behavior depends on the motivation to comply with them. In relation to the behavior it is important to reflect the impact of different normative sources, for example, parental influence on the behavior of young drivers differs significantly from peer influence (Scott-Parker, Watson, \& King, 2009). Deutsch and Gerard (1955) distinguish between two categories of normative influences: descriptive and injunctive. Injunctive norms are the part of the TPB and correspond with the expectations of others in relation to our behavior (e.g. "People whose opinions are important for me would certainly expect that I will not exceed the speed limit"). Descriptive (behavioral) norms are connected with the people tendency to imitate the behavior of others. Applied to speeding behavior, drivers tend to drive faster when others are driving quickly (Cristea, Paran, Delhomme, 2013). Influence of descriptive norms can be explained in terms of the self-categorization theory, which says that people perceive themselves similarly like his own group and individuals will then act according to the views and opinions shared by the whole group to which the driver belongs. According Forward (2009) descriptive norm represents behavior that is considered normal, although it may not be morally right. Descriptive norms are sometimes considered to be a better predictor of behavior or intentions to perform behaviors then injunctive norms (White et al., 2009). Elliot (2001) identifies personal norms as the moral values that people think of as important. That means, before starting a certain behavior they will consider the consequences of that behavior for themselves and their self-image and in case of the inconsistency with their personal norms they might prevent them from doing that behavior.

Perceived behavioral control is the degree to which an individual believes that the behavior is under his or her control (Parker et al., 1992). Also represents the perceived easiness or difficulty to perform that behavior depending on the individual capabilities and external circumstances. Beliefs related to perceived behavioral control may strengthen or weaken intention to speed. For example, for supporting beliefs might be considered "Hurry up, you are late" or "The road is good (direct, unobstructed)." Beliefs that might decrease intention to speed can be considered as "Fines for speeding are high" (Warner, Aberg, 2008). Intention is thus considered as a mediating factor in the association between attitude, subjective norm, perceived behavioral control and behavior, but can also predict behavior directly (Paris, Broucke, 2008).

Previous research showed that 'past behavior' or 'habit formation' plays an important role in explaining traffic safety behavior although it is not a part of traditional TPB-model constructs (Rothengatter, 1993). Well learned skills are performed almost automatically. Driving is also about training and repetition of skills that gradually turn into automatic actions behind the wheel. Habit formation and perceived behavioral control play an 
important role in the attitude-behavior gap and both constructs can have an impact on behavioral intentions and behavior directly. Habit formation leads to 'automatic' or learned behavior, while perceived behavioral control is a cognitive factor that may deliberately lead to a certain behavior. Therefore, both constructs have an important role in explaining traffic safety behavior (Pelsmacker, Janssens, 2007).

The aim of the study was to verify the influence and predictive validity of selected constructs of the extended Theory of Planned Behavior - attitudes, norms, perceived behavioral control, intention and habit (past behavior) on self-reported and actual speeding behavior for male and female drivers.

\section{Method}

\subsection{Participants and procedure}

Our sample consisted of 101 respondents (53,5\% male and 46,5\% female). The age ranges from 19 to 57 $(\mathrm{M}=28 ; \mathrm{SD}=8,9)$. Mean period for which participants has held a driving license was 8,5 years $(\mathrm{SD}=7,6)$. Regarding frequency of driving per week, $47 \%$ of participants reported daily driving, $32 \%$ occasional driving (two-four times per week) and 22\% indicated ones or less time per week. Data were gathered electronically using web based on-line survey. Respondents were addressed through social nets with request to complete online version of the questionnaire using the application "Google Docs". They were assured of anonymity and confidence.The condition for participation in the research was holding the driving license category B and active driving.

\subsection{Measures}

Risk behavior scale: Speeding. Speeding behavior was measured using self-reported behavioral scale developed by Ulleberg a Rundmo (2003) consisted of 6 items. (e.g. „I overtake the car in front when it is driving at the speed limit"). Respondents were asked to indicate how often they perform different types of speeding behavior, ranging from "never" to "very often" on five point Likert scale. A high score on a scale indicated a high degree of speeding.

$T P B$ questionnaire. The selected constructs of TPB model were measured using 10 subscales (Pelsmacker, Janssens, 2007): Attitudes towards speeding (e.g. „Speeding is one of the most important problems in our society"), Attitudes towards speed controls (e.g. „More police controls incite to not speeding“) , Attitudes towards accidents (e.g. „Respecting the speed limits in the built-up area enables me to stop faster in case of an emergency“), Affective attitudes towards speeding (e.g. „Speeding more than $10 \mathrm{~km} / \mathrm{h}$ above the limit gives me a kick"), Subjective norm (e.g. „My partner finds that I may never exceed the speed limit (with more than 10 $\mathrm{km} / \mathrm{h}$ )“, Descriptive norm (e.g. „Respecting the speed limits at all times in the built-up area means that I will drive slower than the stream of traffic"), Nc ative norm (e.g. „It is more important to me to drive like the other road users than to respect the speed limits“), Perceived behavioral control (e.g. „You are unaware of your own speed“), Intention (e.g. „I think I will still exceed the speed limits in the built-up area in future“), Habit (e.g. „Speeding is something I do without thinking“). Respondents indicated their answers on 7-point Likert-type scale $(1=$ totally disagree; $7=$ totally agree $)$.

Demographic measures. Respondents answered questions about their sex, age, annual mileage, number of penalized speeding offences during last three years.

Based on the above mentioned determining factors of speeding behavior the conceptual model of the study is represented in Fig.2. 


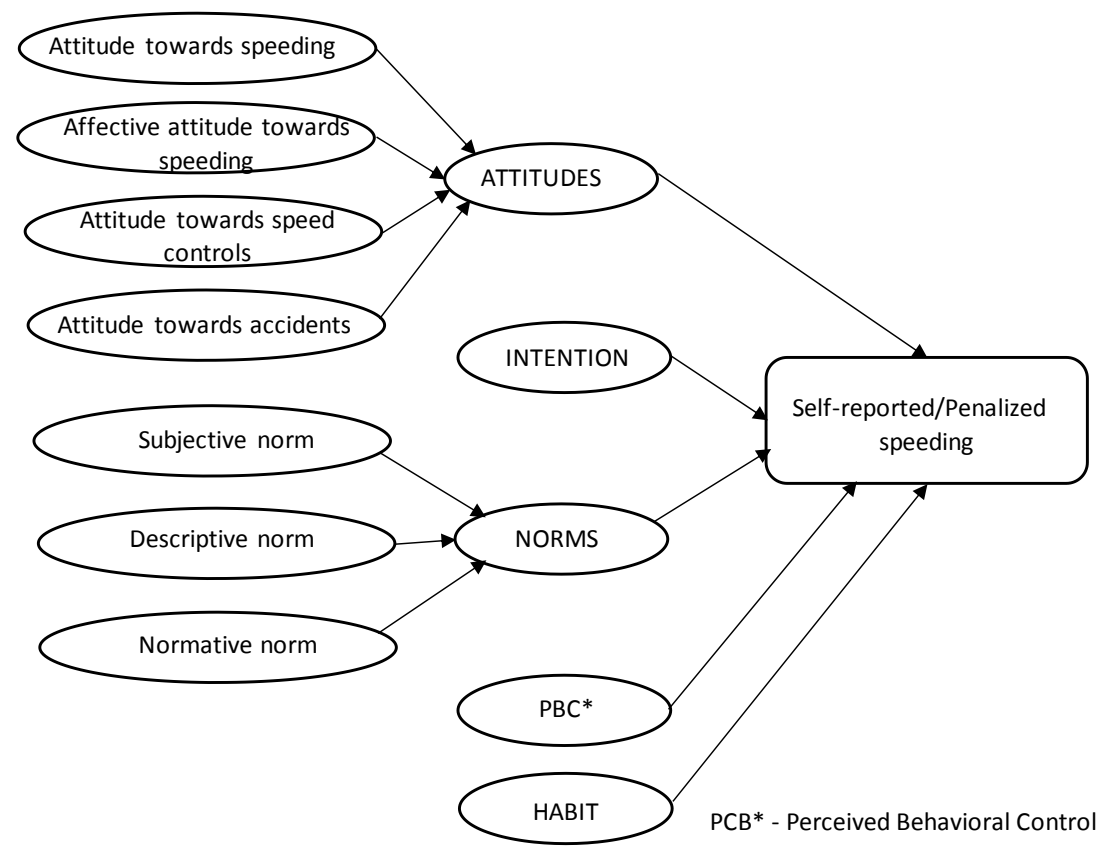

Fig. 2: Conceptual model of the study

\section{Results}

First, the internal consistency using Cronbach's Alpha for each scale/subscale was conducted. Two subscales of the TPD questionnaire demonstrated unsatisfactory internal consistency - Attitude towards speeding $($ Alfa $=.43)$ and Normative norm $($ Alfa $=.51)$ and were excluded from further testing (Table 1$)$.

TABLE I: Number of items and Cronbach's Alpha for each scale

\begin{tabular}{|c|c|c|}
\hline Scale & $\begin{array}{l}\text { Number } \\
\text { of items }\end{array}$ & $\begin{array}{c}\text { Cronbach } \\
\text { Alfa }\end{array}$ \\
\hline Risk behaviour scale: Speeding & 6 & .844 \\
\hline \multicolumn{3}{|l|}{ Attitudes } \\
\hline Affective attitude towards speeding & 4 & .680 \\
\hline Attitude towards speeding & 4 & .432 \\
\hline Attitude towards speed controls & 3 & .847 \\
\hline Attitude towards accidents & 3 & .934 \\
\hline \multicolumn{3}{|l|}{ Norms } \\
\hline Subjective norm & 5 & .902 \\
\hline Descriptive norm & 3 & .709 \\
\hline Normative norm & 2 & .513 \\
\hline Perceived behavioral control & 4 & .779 \\
\hline Habit & 3 & .836 \\
\hline Intention & 3 & .805 \\
\hline
\end{tabular}

Next, correlation analysis (Spearman) for testing the relations between TPB constructs, self-reported and actual speeding behavior was used (Table 1). Correlation analysis showed significant positive relationships at the $1 \%$ level between subjective norms, perceived behavioral control, habit, intention and self-reported speeding. Negative significant relationship we have identified between affective attitudes toward driving fast ("quick ride kicks me, gives me a feeling of excitement") and sex of driver (men reported significantly higher rates for speeding compared to women). Regarding penalized (actual) speeding behavior form the TPB constructs only habit and intention have been identified as significant. Variable age did not any play important role neither for 
self-reported nor for actual speeding behavior. Regarding cognitive attitudes (toward speed control, accidents) the significant relations with speeding behavior have not been identified.

TABLE II: Means, standard deviations (SD), correlation coefficients (Spearman)

\begin{tabular}{|c|c|c|c|c|c|c|c|c|c|c|c|c|c|c|}
\hline & Variable & Mean & SD & 1. & 2. & 3. & 4. & 5. & 6. & 7. & 8. & 9. & 10. & 11. \\
\hline 1. & Sex & 1,47 & 0.5 & & & & & & & & & & & \\
\hline 2. & Age & 28,00 & 1.00 & -.189 & & & & & & & & & & \\
\hline 3 & Affective attitude towards speeding & 14,40 & 5,2 & .189 & 0.88 & & & & & & & & & \\
\hline 4 & Attitude towards speed controls & 12,90 & 4,9 & -.073 & $.215^{*}$ & -.063 & & & & & & & & \\
\hline 5 & Attitude towards accidents & 15,90 & 5,3 & .040 & -.010 & $.337^{* *}$ & $.206^{* *}$ & & & & & & & \\
\hline 6 & Subjective norm & 25,50 & 7,9 & $-.213^{*}$ & .069 & $-.254^{* *}$ & .077 & .013 & & & & & & \\
\hline 7 & Descriptive norm & 10,40 & 3,8 & -.043 & $.206^{*}$ & -.077 & .175 & -.027 & -.074 & & & & & \\
\hline 8 & Perceived behavioral control & 18,20 & 5,6 & -.002 & -.082 & $-.452^{* *}$ & $.205^{*}$ & -.040 & $.360^{* *}$ & .113 & & & & \\
\hline 9 & Habit & 9,90 & 4,9 & $-.200^{*}$ & .085 & $-.295^{* *}$ & -.021 & -.096 & $.471^{* *}$ & .109 & $.567^{* *}$ & & & \\
\hline 10 & Intention & 11,40 & 4,7 & -.105 & $-.230^{* *}$ & $-.256^{* *}$ & -.163 & $-.212^{* *}$ & $.400^{* *}$ & -.051 & $.282^{* *}$ & $.304^{* *}$ & & \\
\hline 11 & Risk behaviour scale: Speeding & 19,40 & 8,4 & $-.356^{* *}$ & -.024 & $-.455^{* *}$ & 0.025 & -.031 & $.627^{* *}$ & .069 & $.544^{* *}$ & $.724^{* *}$ & $.429^{* *}$ & \\
\hline 12 & Penalized speeding behavior & 0,58 & 0,6 & -.113 & -.019 & -.087 & 0.070 & -.066 & $.222^{*}$ & .037 & .178 & $.359^{* *}$ & $.212^{*}$ & $.325^{* *}$ \\
\hline
\end{tabular}

$* \mathrm{p}<.05, * * \mathrm{p}<.01$.

In the last step, two separated hierarchical regression analysis were conducted to test predictive value of the TPB constructs on two outcomes variables - self-reported and penalized (actual) speeding behavior. As shown in table 3, sex, perceived behavioral control, intention and habit were significantly related to self-reported speeding, whereas affective attitude towards speeding in conjunction with other variables lost on its predictive power and in the regression model was insignificant. Predictive value of the model was rather strong and accounted for $69,5 \%\left(\mathrm{R}^{2}=.695\right)$ of variability.

TABLE III: Hierarchical regression analysis on self-reported speeding

\begin{tabular}{llcccc}
\hline & Prediktors/variables & $\mathrm{R}^{2}$ & $\mathrm{~F}$ & Beta & Sig. \\
\hline \hline Step1 & Sex & 12,7 & 15,5 & -0.368 & 0,000 \\
Step2 & Affective attitude towards speeding & 69,5 & 38,91 & 0,039 & 0,512 \\
& Subjective norm & & & 0,140 & 0,048 \\
& Perceived behavioral control & & & 0,162 & 0,023 \\
Habit & & & 0,446 & 0,000 \\
Intention & & & 0,275 & 0,000 \\
\hline \hline
\end{tabular}

Similarly, we tested regression model for penalized (actual) speeding behavior. In this model only variable habit was significantly associated with penalized speeding. Predictive value for this model was rather weak and accounted only for $11,9 \%\left(\mathrm{R}^{2}=.119\right)$ of variability (table 4$)$.

TABLE IV: Hierarchical regression analysis on penalized speeding (actual behavior)

\begin{tabular}{llcccc}
\hline & Prediktors/variables & $\mathrm{R}^{2}$ & $\mathrm{~F}$ & Beta & Sig. \\
\hline \hline Step1 & Subjective norm & 11,9 & 3,2 & 0,073 & 0,704 \\
& Perceived behavioral control & & & 0,083 & 0,531 \\
Habit & & & 0,291 & 0,020 \\
Intention & & & 0,112 & 0,289 \\
\hline
\end{tabular}

\section{Discussion}

In the presented study we used the extended version of the Theory of Planned Behavior to verify the predictive value of the selected constructs - attitudes, norms, perceived behavioral control, intention and habit on self-reported and penalized (actual) speeding behavior. Correlation analysis confirmed our assumptions about the relationship of negative attitudes towards speeding, subjective norms, intentions and past behavior / habit on 
self-reported speeding behavior. Regression model on self-reported speeding identified four important variables: sex, subjective norm, intention and habit and accounted for $69.5 \%$ of variance. In case of the penalized speeding only habit/past behavior was identified as significant.

Some of our results are consistent with what would be expected. E.g. Pelsmacker and Janssens (2007) verified positive significant relationship between the intention and self-reported speeding. Elliott et al. (2007) identified a positive correlation between the intention and speeding measured by simulator.

Regarding the attitudes, an affective attitude was only variable with relations to self-reported speeding, which means that positive affective outcomes in terms of pleasure, excitement, and happiness played an expected supportive role for ones engagement in speeding behavior. On the other hand, cognitive attitudes (attitude towards speed controls, attitude towards accidents) did not show any relations with speeding, while empirical evidence for the predictive value of cognitive attitudes in relation to driving behavior have been found in a wide range of studies. An interpretation could be that we measured risky, violent behavior (speeding) and attitudes towards them which represent sensitive information about the individual, and the respondents may choose not to report such behaviors in order to present themselves in a socially desirable way despite of declared anonymity of the study. Another explanation is that behavior/speeding was measured at the same time as the attitudes were measured.

Further we assumed that speeding behavior was influenced by the norms with respect to their promotion by important reference groups / normative sources (friends, partners, parents 'important people', and passengers). We identified significant relation between subjective norms and speeding, the effect of descriptive norms was insignificant, which means, that for our respondents the significant "others" play more important role in driving behavior then the other drivers and the imitation of their behavior. Results of this study partially confirm earlier suggestions on the importance and relevance of various normative frameworks (e.g. Pelsmacker, Janssens, 2007)). Our different findings can be interpreted from the following perspectives. Subjective norms were measured by five items, each item measured different normative source; descriptive norms we measured with the low number of items (3); normative norm scale showed insufficient reliability, we excluded it from further testing. The results may also reflect the not normally age distribution of the sample and its small size, as well. Finally, it is important to realize that the speeding compared to other forms of risky behavior (e.g. driving under the influence of alcohol) is despite its possible negative effects less socially stigmatized, which also supports the fact that this type of behavior could be legitimized by social norms as an acceptable behavior.

In the context of the model TPB drivers may or may not be convinced that they have driving skills enabling them to speed and to have their behavior under control. These considerations then result into intentions to adapt or not to adapt their speed to the official limits, which also acts as a very important proximal determinant of subsequent behavior that will be performed (Paris, Broucke 2008). Our findings support the above and document a significant correlation between perceived behavioral control and intention, and self-reported behavior.

Finally, habit or past behavior was identified as the most important on self-reported and penalized speeding behavior. Our results in the linear regression model confirmed very strong predictive power of the past behavior on speeding. These results confirm earlier suggestions. E.g. Conner, Smith, McMillan (2003) presented similar findings, past behavior and perceived behavioral control were the best predictors of speeding.

\section{Conclusion}

The presented results allow to say that the Theory of Planned Behavior would be an appropriate, reliable tool for predicting speeding behavior and to measure cognitive constructs in relation to the self-reported violation of speed, as well. We realize the limits of the study especially connected with the size of the sample, the above mentioned methodological constrains and the fact that operationalized dimensions of TPB were validated only on self-reported data which may limit their predictive value for applicability into real behavior.

\section{Acknowledgement}

This work has been supported by the Ministry of Education, Science, Research and Sport of the Slovak Republic (VEGA 1/0545/14). 


\section{References}

[1] Ajzen, I. The Theory of Planned Behavior. Organizational Behavior and Human Decision Processes, 50 (2), 179-211, 1991.

http://dx.doi.org/10.1016/0749-5978(91)90020-T

[2] Armitage, CH. J. and Conner, M. Efficacy of the theory of planned behavior: A meta-analytic review. British Journal of Social Psychology. 40 (4), 471-499, 2001.

http://dx.doi.org/10.1348/014466601164939

[3] Castanier, C. and Deroche, T, Woodman, T. Theory of planned behavior and road violations: The moderating influence of perceived behavioral control. Transportation Research Part F. 18 (1), 148-158, 2013.

http://dx.doi.org/10.1016/j.trf.2012.12.014

[4] Conner, M. and Armitage, CH. J. Extending the Theory of Planned Behavior: A Review and Avenues for Further Research. Journal of Applied Social Psychology. 28 (15), 1429-1464, 1998.

http://dx.doi.org/10.1111/j.1559-1816.1998.tb01685.x

[5] Conner, M., Smith, M. and McMillan, B. Examining Normative Pressure in the Theory of Planned Behavior: Impact of Gender and Passengers on Intentions to Break the Speed Limit. Current Psychology: Developmental, Learning, Personality, Social. 22 (3), 252-263, 2003.

http://dx.doi.org/10.1007/s12144-003-1020-8

[6] Cristea, M., Paran, F. and Delhomme, P. Extending the theory of planned behavior: The role of behavioral options and additional factors in predicting speed behavior. Transportation Research Part F, 21 (1), 122-132, 2013.

http://dx.doi.org/10.1016/j.trf.2013.09.009

[7] Deutsch, M. and Gerard, H. A study of normative and informational social influences upon individual judgment. The Journal of Abnormal and Social Psychology, 51(3), 629-636, 1955.

http://dx.doi.org/10.1037/h0046408

[8] Dinh, D. D. and Kubota, H. Profile-speed data-based models to estimate operating speeds for urban residential streets with a $30 \mathrm{~km} / \mathrm{h}$ speed limit. IATSS Research 36, 115-122, 2013.

http://dx.doi.org/10.1016/j.iatssr.2012.06.001

[9] Elliot, B. The application of the Theorists' Workshop Model of Behavior Change to motorists' speeding behavior in Western Australia. Unpublished report, Western Australia, Office of Road safety, Department of Transport, 2001.

[10] Fishbein, M. and Ajzen, I. Belief, Attitude, Intention, and Behavior: An Introduction to Theory and Research. Addison-Wesley, Reading, MA, 1975.

[11] Forward, S. E. The theory of planned behavior: The role of descriptive norms and past behavior in the prediction of drivers' intentions to violate. Transportation Research Part F. 12 (3), 198-207, 2009.

http://dx.doi.org/10.1016/j.trf.2008.12.002

[12] Parker, D. et al. Intention to commit driving violations: an application of the Theory of planned behavior. Journal of Applied Psychology. 77 (1), 94-101, 1992.

http://dx.doi.org/10.1037/0021-9010.77.1.94

[13] Pelsmacker, P. D. and Janssens, W. The effect of norms, attitudes and habits on speeding behavior: Scale development and model building and estimation. Accident Analysis and Prevention. 39 (1), 6-15, 2007.

http://dx.doi.org/10.1016/j.aap.2006.05.011

[14] Rothengatter, J.A. Road user attitudes and behavior. In: Grayson, G.B. (Ed.), Behavioral Research in Road Safety III. Transport Research Laboratory, Crowthorne, UK, pp. 128-134, 1993.

[15] SARTRE 3. European drivers and road risk: Part 1 - Report on principal analysis [online]. [cit.2015-24-06], 2004. http://ec.europa.eu/transport/road_safety/specialist/knowledge/pdf/ref_53_sartre_3_part_1.pdf

[16] Scott-Parker, B., Watson, B., and King, M. Understanding the psychosocial factors influencing the risky behavior of young drivers. Transportation Research: Part F, 12(6), 470-482, 2009.

http://dx.doi.org/10.1016/j.trf.2009.08.003

[17] Ulleberg, P. and Rundmo, T. Personality, attitudes and risk perception as predictors of risky driving behavior among young drivers. Safety Science. 41 (5), 427-443, 2003.

http://dx.doi.org/10.1016/S0925-7535(01)00077-7 
[18] Warner, H. W. and Åberg, L. Drivers' beliefs about exceeding the speed limits. Transportation Research Part F. 11 (5), 376-389, 2008.

http://dx.doi.org/10.1016/j.trf.2008.03.002

[19] White, K. M., Smith, J. R., Terry, D. J., Greenslade, J. H. and McKimmie, B. M. Social influence in the theory of planned behavior: The role of descriptive, injunctive, and in-group norms. British Journal of Social Psychology, 48(1), 135-158, 2009.

http://dx.doi.org/10.1348/014466608X295207 